\title{
A Comparative Study Between the Goldmann Applanation Tonometer and the Non-Contact Air-Puff Tonometer (Huvitz HNT 7000) in Normal Eyes
}

This article was published in the following Dove Press journal: Clinical Ophthalmology

\section{Ricardo Alexandre Stock (iD) Carine Ströher \\ Rodrigo Rosa Sampaio Rafael André Mergener (D) Elcio Luiz Bonamigo}

Medical School of the University of the West of Santa Catarina (Universidade do Oeste de Santa Catarina - UNOESC), Joaçaba, Santa Catarina, Brazil
Correspondence: Ricardo Alexandre Stock

Belotto Stock Centro Oftalmológico, Rua Rio Branco, 589, Centro, CEP: 89 , Joaçaba, SC, 600-000, Brazil

Tel + 554935220788

$\mathrm{Fax}+554935225059$

Email ricardostockreal@gmail.com
Objective: To assess whether the non-contact air-puff tonometer (NCT) is an appropriate alternative to the Goldmann applanation tonometer (GAT) for measuring intraocular pressure (IOP).

Patients and Methods: An observational, cross-sectional, and comparative study with a quantitative approach was carried out. Two techniques for IOP measurements using the standard GAT and the NCT were compared. A total of 180 eyes from 90 patients were included in the study.

Results: The total mean IOP according to NCT measurements was $14.12 \mathrm{mmHg}$, and the total mean IOP according to the GAT was $12.98 \mathrm{mmHg}$; these values were significantly different $(\mathrm{p}=0.0018)$. When dividing the participants into three groups according to the measurement range obtained and comparing the mean NCT and GAT measurements in each group, in Group $1(10-15 \mathrm{mmHg})$, no statistically significant difference was found between the means of the two tonometers $(\mathrm{p}=0.3100)$, a difference was observed between Group $2(16-19 \mathrm{mmHg})$ and Group $3(20 \mathrm{mmHg}$ or more $)(\mathrm{p}<0.001)$. When dividing the participants by age group, the means obtained by the two tonometers also differed significantly between Group 4 (40-59 years) and Group 5 (60 years or more) $(p<0.0001)$. In all groups, the mean measurements by the NCT were higher than those by the GAT.

Conclusion: The NCT presented an approximate mean of the measures with the GAT in group 1 but was overestimated in the measurements of the groups 2 and 3 .

Keywords: ocular tonometry, glaucoma, ocular hypertension, intraocular pressure, efficiency

\section{Plain Language Summary}

Glaucoma is one of the major causes of blindness in the world even though, in most cases, it is a controllable desease. One method of detecting the disease is measuring high intraocular pressure using tonometers, one of the manifestations of glaucoma, although there are others, also important, such as changes in the visual field and optic nerve. Some tonometers directly contact the eyes, requiring instillation of anaesthetic eye drops and fluorescein for their use, while others do not contact the eyes and are easier to use but are less accurate. The ease of obtaining intraocular pressure measurements using non-contact air-puff tonometers for the early diagnosis of glaucoma motivates studies on how these devices perform relative to the standard measuring instrument - the Goldmann tonometer. The non-contact tonometer overestimates the measurement at higher pressures, does not replace the Goldmann tonometer, 
but can be used for screening due to its easier use when compared to the Goldmann tonometer.

\section{Introduction}

The decision to treat glaucoma is directly influenced by intraocular pressure (IOP) measurements, emphasizing the need to obtain accurate measurements. Decisions based on false-positive or false-negative diagnoses of glaucoma can have severe consequences because the damage caused to the optic nerve is irreversible. ${ }^{1\left(p .{ }^{12}\right)}$ On the other hand, unnecessary exposure to potentially harmful medications can generate inappropriate anxiety and waste resources, rendering the discussion about the modalities of medical equipment that best support the diagnosis of glaucoma very timely.

IOP is the hydrostatic pressure exerted by the aqueous humour in the intraocular tissues as a result of the balance between production and drainage. IOP varies between individuals and between the eyes of the same individual. The mean IOP in adult populations is estimated to be between $15 \mathrm{mmHg}$ and $16 \mathrm{mmHg}$, with a standard deviation (SD) of $2.5 \mathrm{mmHg}$ to $2.8 \mathrm{mmHg}^{2}$; however, values below $21 \mathrm{mmHg}$ are considered normal. ${ }^{1\left(\text { p. }^{33)}\right.}$ IOP measurement is part of the basic ophthalmological evaluation since ocular hypertension is the main risk factor for the onset and development of glaucoma, which is the only modifiable risk factor. $^{3(p .}$ 128),4(p. 20) Lowering IOP is a proven method to delay or stop the progression of glaucoma and thereby reduce visual loss, thus preserving patients' quality of life. ${ }^{5}$

The slit lamp-mounted Goldmann applanation tonometer (GAT) is the most commonly used instrument to measure IOP and is currently considered the reference instrument, ie, the most accurate and recommended standard to which all other tonometers are compared. ${ }^{1(\mathrm{p} .}$ 33) However, it should be noted that even the measurement made with the standard tonometer (GAT) is not precise since its values are significantly lower than the intracameral pressure. ${ }^{6}$

On the other hand, the non-contact air-puff tonometer (NCT) is simpler to operate, is non-invasive, does not reduce IOP by the massage effect, and does not require prior anaesthetic instillation, all of which contribute to increased comfort, reduced damage to the corneal surface, and a lower risk of contamination. ${ }^{2,6}$ The measurement requires only a few fractions of a second and is completed when the sensor receiver detects the light being reflected in the cornea; the measured value is shown on an LCD screen or a touch screen depending on the model.

Early identification of patients with glaucoma can delay their blindness process from 23 to 35 years, supporting the adoption of methods that facilitate IOP measurement on a large scale as is possible with the $\mathrm{NCT}^{2}$ In this context, the present study aimed to analyse whether the NCT is an appropriate alternative to the GAT to measure IOP.

\section{Patients and Methods}

A retrospective, cross-sectional, and comparative study with a quantitative approach was performed. Two IOP measurement techniques were compared: the standard GAT and the NCT.

The study was conducted at the Centro Oftalmológico Belloto Stock (Belloto Stock Ophthalmological Centre) COBS during routine ophthalmologic visits and included 180 eyes of 90 patients. Before data collection, the participants received verbal information about the procedures involved. All patients signed an informed consent.

The medical devices used in the study were the NCT Huvitz HNT 7000 (Republic of Korea) and the GAT HS Haag-Streit Diagnostics (Switzerland). For the examination, Anestalcon anaesthetic eye drops $(5 \mathrm{mg} / \mathrm{mL}$ proxymetacaine hydrochloride) were used. The medical equipment was calibrated prior to the examination.

The target population consisted of patients aged 40 years or older with healthy eyes. The exclusion criteria were patients with previous eye diseases, glaucoma patients or eye with $20 \mathrm{mmh}$ or more measured by TAG, eye drop users, and patients diagnosed with some systemic disease, such as diabetes or rheumatic diseases, during the first visit.

The IOPs of both eyes of each patient were evaluated, first on the right and then on the left and each eye was used as one isolated data. The NCT measurement was always performed before the GAT measurement to eliminate the effect of ocular massage, which has been described when using the GAT and is absent with the NCT. ${ }^{6}$ The patients were selected randomly and sequentially from February 2019 to February 2020.

After performing tonometry with both devices, the values were tabulated and statistically analysed using the statistical programme Bioestat 5.3. For data analysis, the MannWhitney test was used for the difference between the IOP measures at a significance level of 5\%. The groups were considered different when the comparison of the mean IOP measurements resulted in $\mathrm{p} \leq 0.05$. 


\section{Results}

A total of 180 eyes from 90 patients with healthy eyes were included in the study. Of the 90 patients, 51 were female and 39 were male. The total mean IOP with the NCT was $14.12 \mathrm{mmHg}$, with an $\mathrm{SD}$ of \pm 3.41 , a minimum value of $8 \mathrm{mmHg}$, and a maximum value of $23 \mathrm{mmHg}$. The total mean IOP with the GAT was $12.98 \mathrm{mmHg}$, with an $\mathrm{SD}$ of \pm 2.93 , a minimum IOP value of $9 \mathrm{mmHg}$, and a maximum value of $19 \mathrm{mmHg}$.

The IOPs measured by the NCT and GAT were divided into three groups. For Group 1 (Table 1), IOPs between 10 and $15 \mathrm{mmHg}$ were selected, totalling 123 eyes. In this group, the total mean IOP measured by the NCT was $12.22 \mathrm{mmHg}$ ( $\mathrm{SD} \pm 1.85$ ), and that measured by the GAT was $12.12 \mathrm{mmHg}$ ( $\mathrm{SD} \pm 2.50$ ). In Group 2 (Table 2), IOPs between 16 and 19 $\mathrm{mmHg}$ were selected, with total mean IOPs of $17.36 \mathrm{mmHg}$ $(\mathrm{SD} \pm 1.19)$ by the $\mathrm{NCT}$ and $14.39 \mathrm{mmHg}(\mathrm{SD} \pm 2.83)$ by the GAT, totalling 47 eyes. In Group 3 (Table 3), patients with IOPs of $20 \mathrm{mmHg}$ or more were included, with total mean IOPs of $21.3 \mathrm{mmHg}(\mathrm{SD} \pm 1.05)$ by the NCT and $17.5 \mathrm{mmHg}$ $(\mathrm{SD} \pm 1.08)$ by the GAT, totalling 10 eyes.

According to age, patients were divided into two groups: Group 4, patients aged between 40 and 59 years, totalling 96 eyes, and Group 5, patients aged 60 years or older, totalling 84 eyes. In Group 4, the mean IOPs were $14.29 \mathrm{mmHg}(\mathrm{SD} \pm 2.82)$ by the NCT and $12.85 \mathrm{mmHg}$ $(\mathrm{SD} \pm 2.50)$ by the GAT. In Group 5, the mean IOPs were $14.03 \mathrm{mmHg}(\mathrm{SD} \pm 3.87)$ by the NCT and $13.27 \mathrm{mmHg}$ $(\mathrm{SD} \pm 3.10)$ by the GAT.

Table I Comparison of the Mean and Standard Deviation of IOP Between 10 and $15 \mathrm{mmHg}$ Measured by the Non-Contact AirPuff Tonometer (NCT) Relative to the Goldmann Applanation Tonometer (GAT)

\begin{tabular}{|l|l|l|l|}
\hline & NCT $(\mathbf{m m H g})$ & GAT $(\mathbf{m m H g})$ & $\boldsymbol{p}$ value \\
\hline Mean & 12.22 & 12.12 & 0.3100 \\
Standard deviation & 1.85 & 2.50 & \\
\hline
\end{tabular}

Table 2 Comparison of the Mean and Standard Deviation of IOP Between 16 and $19 \mathrm{mmHg}$ Measured by the Non-Contact AirPuff Tonometer (NCT) Relative to the Goldmann Applanation Tonometer (GAT)

\begin{tabular}{|l|l|l|l|}
\hline & NCT $(\mathbf{m m H g})$ & GAT $(\mathbf{m m H g})$ & $\boldsymbol{p}$ value \\
\hline Mean & 17.36 & 14.39 & $<0.0001$ \\
Standard deviation & 1.19 & 2.83 & \\
\hline
\end{tabular}

Table 3 Comparison of the Mean and Standard Deviation of Intraocular Pressure (IOP) of $20 \mathrm{mmHg}$ or More Measured by the Non-Contact Air-Puff Tonometer (NCT) Relative to the Goldmann Applanation Tonometer (GAT)

\begin{tabular}{|l|l|l|l|}
\hline & NCT $\mathbf{( m m H g )}$ & GAT $\mathbf{( m m H g})$ & p value \\
\hline Mean & 21.3 & 17.5 & $<0.001$ \\
Standard deviation & 1.05 & 1.08 & \\
\hline
\end{tabular}

\section{Discussion}

When comparing the total mean IOP, the value obtained by the NCT $(12.12 \mathrm{mmHg})$ was greater than the mean obtained by the GAT at $1.98 \mathrm{mmHg}$, and this difference was statistically significant $(p=0.0018)$. However, when dividing the patients into three groups according to the pressure obtained, in Group $1(10-15 \mathrm{mmHg})$, no statistically significant difference was found between the total mean IOP measurements obtained with the NCT and the GAT ( $p=0.3100$ ); that is, the IOP measurements with both devices were similar in the range of 10 to $15 \mathrm{mmHg}$ (Table 1).

A similar result was found in three other studies, which did not divide the participants by pressure range and obtained NCT results comparable to those of the GAT except at extreme pressures, although the mean NCT values were slightly higher. ${ }^{7-9}$ However, a study conducted with the same device (Huvitz HNT-7000) found lower values relative to GAT measurements in healthy participants aged between 20 and 25 years, but the authors warned that other studies found higher values, as observed in the present study and that the measurements may be influenced by both human factors and the models (as well as the units) of the devices used. ${ }^{10}$

However, the correlation between the mean IOPs obtained by the NCT in Group $2(16-19 \mathrm{mmHg})$ and in Group 3 (20 mmHg or more) was higher than that found with the GAT, and the differences were statistically significant ( $<<0.0001$ ), showing that in these groups, the NCT overestimated the IOP (Tables 2 and 3). This result is consistent with two other studies that found results similar to those of the GAT at measurements between 10 and 20 $\mathrm{mmHg}$, although the accuracy decreased at the higher values. ${ }^{11,12}$

NCT measurements are influenced by corneal thickness but are highly related to GAT measurements as shown by another study in both patients with ocular hypertension $(p=0.086)$ and patients with primary open-angle glaucoma, with no significant difference between groups $(\mathrm{p}=0.1112)$, 
although the NCT measurements were slightly higher than the GAT measurements, and a difference in the measurements of the control group was found $(p=0.033) .{ }^{13}$ Regarding thickness, a study showed that NCT values were higher than GAT values in thin and normal corneas, but that IOP was overestimated in thicker corneas. ${ }^{14}$

Glaucoma is prevalent among older people. Therefore, an analysis by age group was performed. In Group 4 (40-59 years) and Group 5 (60 years or more), as in Group 2 (16-19 mmHg) and Group 3 (over 19 mmHg), a statistically significant difference $(\mathrm{p}<0.0001)$ was found between the total mean IOP measurements obtained by the NCT, which were higher, and the total mean IOP measurements obtained by the GAT, which were lower. This result is consistent with a study that found a significant difference and an increase in IOP measurements for both devices with increasing age, which were not found in the present study. ${ }^{15}$

However, the equipment does not perform equally, and NCT measurements may vary according to the brand and model of the device used. Therefore, the results were compared by the brands of devices studied in articles containing information about brands, results, statistical analyses, and participant characteristics to build the theoretical framework (Table 4).

Two studies comparing the same brand of device, but different models (Topcon CT-60 ${ }^{13}$ and CT-80) ${ }^{9}$ showed more accurate measurements with the latest model (CT80) without a significant difference relative to GAT measurements; however, the participants in this group (CT-80) were young, between 20 and 27 years old, with lower mean pressures, which may have influenced the accuracy. In another study with a Topcon CT 80 tonometer including patients with all pressure levels, the mean IOP measured by the NCT was higher than that measured by the GAT (15.91 $\mathrm{mmHg} \times 13.01 \mathrm{mmHg}$ ), and the difference was significant, suggesting that an increase in IOP increases the inaccuracy of the NCT (Table 4). ${ }^{16}$

A study using the Nidek NT-530 model in participants with a mean IOP below $21 \mathrm{mmHg}$ showed no difference relative to the GAT ( $p=0.998)$ as observed in Group 1 in the present study (Tables 1 and 4). ${ }^{8}$ However, two other studies using the Nidek SL-300 and Tonoref Nidek II models in patients with all IOP levels found a significant difference between the NCT and GAT $(p \leq 0.001$ and $\mathrm{p}<0.01$, respectively) as observed in Groups 2 and 3 in the present study (Tables 2 and 3), showing that participant characteristics and the model of devices of the same brand can influence the results (Table 4). ${ }^{15,17}$

Reliable results relative to GAT results for Goldmanncorrelated intraocular pressure (IOPg) were obtained with the Reichert PT-100 ( $\mathrm{p}=0.64)^{7}$ and Reichert CR7 ( $\left.\mathrm{p}=0.52\right)$ even in patients with all pressure levels, although lower accuracy was achieved when considering the cornealcompensated IOP (IOPcc) modality in Reichert CR7 $(\mathrm{p}<0.01)$ (Table 4). ${ }^{18}$

A study with the Corvis ST tonometer including patients with all pressure levels obtained means similar to those of the GAT, with no significant difference between the tonometers $(p=0.1162) .{ }^{19}$ However, these results do not agree with the findings of another study with glaucoma patients with all pressure levels, which obtained lower values with a device of the same brand and model (Corvis ST) for both the corrected IOP based on corneal thickness (IOPpachy) and IOPcc measurements $(p<0.01)$, perhaps because these units do not operate exactly the same, and technical or human factors affect the measurements (Table 4). ${ }^{18}$

A recent study confirmed that no significant difference existed between the Tomey FT-1000 and the GAT for measurements below $21 \mathrm{mmHg}(\mathrm{p}=0.151)$, which is similar to the observations in Group 1 in the present study, but when measurements were equal to or greater than 21 $\mathrm{mmHg}$, the NCT obtained significantly lower values than the GAT ( $p=0.016)$ in contrast to the observations in the present study. ${ }^{18}$ In another study conducted with a different NCT model (Thomey NCT) in which participants were not divided by pressure group, a difference relative to GAT was found ( $\mathrm{p}<0.001$ ), with the NCT yielding lower values. ${ }^{20}$

A study analysing the Canon Full Auto Tonometer TX$\mathrm{F}$ in patients aged 16 to 78 years without stratification by pressure group also found a higher mean value obtained by the NCT than by the GAT, with values of $18.17 \mathrm{mmHg}$ and $15.59 \mathrm{mmHg}$, respectively, which may have contributed to the significant difference between groups $(p=0.003)$ (Table 4). ${ }^{20,21}$ Accordingly, a study evaluating the repeatability and reproducibility of the Reichert PT-100 tonometer in young patients showed exactly the same mean results between the NCT and GAT in the first measurement (a mean of $15 \mathrm{mmHg}$ for both instruments), corroborating the finding that NCT results are more reliable at lower IOP levels. $^{6}$

In general, as shown in Table 4, seven of the thirteen devices showed no significant differences relative to the 
Table 4 Comparative Results of the Non-Contact Air-Puff Tonometer (NCT) Relative to the Goldmann Applanation Tonometer (GAT) by the Brand/Model of Device from 2005 to 2020

\begin{tabular}{|c|c|c|c|c|c|c|}
\hline Year & Authors & $\begin{array}{l}\text { NCT Brand } / \\
\text { Model }\end{array}$ & $\begin{array}{l}\text { NCT } \\
\text { Measurement } \\
\text { in } \mathbf{m m H g}\end{array}$ & $\begin{array}{l}\text { GAT } \\
\text { Measurement } \\
\text { in } \mathbf{m m H g}\end{array}$ & $p$ & Participants \\
\hline \multirow[t]{3}{*}{2021} & \multirow{3}{*}{$\begin{array}{l}\text { Stock et al (This } \\
\text { research) }\end{array}$} & \multirow{3}{*}{$\begin{array}{l}\text { Huvitz HNT } \\
7000^{\mathrm{a}}\end{array}$} & 12.22 & 12.12 & 0.3100 & Group I: $10-15 \mathrm{mmHg}$ \\
\hline & & & 17.36 & 14.39 & $<0.000$ I & Group 2: $16-19 \mathrm{mmHg}$ \\
\hline & & & 21.30 & 17.50 & $<0.001$ & Group 3: $\geq 20 \mathrm{mmHg}$ \\
\hline \multirow[t]{2}{*}{2020} & \multirow{2}{*}{$\begin{array}{l}\text { Trakanwitthayarak } \\
\text { S }\end{array}$} & \multirow{2}{*}{$\begin{array}{l}\text { Tomey } \\
\text { FT- } 1000^{\mathrm{a}}\end{array}$} & 14.14 & 13.60 & 0.151 & Group $\mathrm{I}:<21 \mathrm{mmHg}$ \\
\hline & & & 30.21 & 35.12 & 0.016 & Group 2: $\geq 21 \mathrm{mmHg}$ \\
\hline \multirow[t]{2}{*}{2019} & \multirow[t]{2}{*}{ Luebke et al } & Corvis $\mathrm{ST}^{\mathrm{a}}$ & 18 & 17.6 & 0.1162 & \multirow{2}{*}{$\begin{array}{l}\text { Outpatients with a mean age of } 66.9 \\
\text { years }\end{array}$} \\
\hline & & Thomey NCT & 16.3 & 17.6 & $<0.001$ & \\
\hline \multirow[t]{4}{*}{2017} & \multirow[t]{4}{*}{ Nakao et al } & $\begin{array}{l}\text { Corvis ST- } \\
\text { IOPpachy }\end{array}$ & 10.3 & 13.6 & $<0.01$ & \multirow[t]{4}{*}{$\begin{array}{l}\text { Patients with primary open-angle } \\
\text { glaucoma with a mean age of } 61.94 \text { years }\end{array}$} \\
\hline & & Corvis ST-IOPcc & 9.7 & 13.6 & $<0.01$ & \\
\hline & & $\begin{array}{l}\text { Reichert 7CR- } \\
\text { IOPg }^{\mathrm{a}}\end{array}$ & 13.7 & 13.6 & 0.52 & \\
\hline & & $\begin{array}{l}\text { Reichert 7CR- } \\
\text { IOPcC }\end{array}$ & 15.5 & 13.6 & $<0.01$ & \\
\hline \multirow[t]{2}{*}{2017} & \multirow[t]{2}{*}{ Jacob et al } & \multirow[t]{2}{*}{ Tonoref Nidek II ${ }^{\mathrm{b}}$} & $<13 \mathrm{mmHg}$ & $>$ GAT & \multirow[t]{2}{*}{$<0.001$} & \multirow[t]{2}{*}{ Patients aged 20 to 60 years } \\
\hline & & & $\geq 13 \mathrm{mmHg}$ & $<$ GAT & & \\
\hline 2016 & Mahsud et al & $\begin{array}{l}\text { Canon Full Auto } \\
\text { Tonometer TX-F }\end{array}$ & 18.17 & 15.59 & 0.003 & Patients aged 16 to 78 years \\
\hline 2016 & Tolomei et al & Nidek SL-300 & 22.77 & 17.79 & $<0.001$ & Patients with a mean age of 51.6 years \\
\hline 2014 & Ilmaz et al & Nidek NT-530 ${ }^{\mathrm{a}}$ & 16.1 & 15.5 & 0.998 & $\begin{array}{l}\text { Patients without glaucoma, with IOP }<2 \text { I } \\
\mathrm{mmHg}\end{array}$ \\
\hline 2013 & Farhood QK & Topcon CT 80 & 15.91 & 13.06 & 0.001 & Outpatients aged 15 to 84 years \\
\hline 2009 & Salim et al & Reichert PT- $100^{\mathrm{a}}$ & 15.0 & 14.3 & 0.64 & $\begin{array}{l}\text { Patients without glaucoma with a mean } \\
\text { age of } 62.6 \text { years }\end{array}$ \\
\hline 2006 & Ogbuehi CK & Topcon CT $80^{\mathrm{a}}$ & 13.6 & 13.4 & $>0.05$ & University students aged 20 to 27 years \\
\hline 2005 & Ko et al & Topcon CT-60 & 16.6 & 15.5 & $<0.001$ & Patients older than 18 years \\
\hline
\end{tabular}

Notes: a Devices that showed no difference relative to the Goldman tonometer in at least one of their measurement methods or one of the groups of participants. ${ }^{b}$ For values below $13 \mathrm{mmHg}$, the NCT obtained higher values than the GAT, and for values equal to or above $13 \mathrm{mmHg}$, the NCT values were lower than the GAT values.

GAT $(\mathrm{p}<0.05)$ in at least one of its measurement methods (when the device had more than one) as observed in Group 1 in the present study, which had lower pressure values, contributing to the similarity of the results.

However, six NCT devices showed differences relative to the GAT ( $>0.05)$ as observed in the other groups in the present study, suggesting that in addition to the technical, human, pressure, and corneal thickness factors involved in the measurements, the NCT brand, unit, and model can also influence the results. On the other hand, in addition to the risk of infection, inaccuracies can also occur during measurements with the GAT due to calibration defects, incorrect techniques, a tight collar or tie, the Valsalva manoeuvre, breath holding, constricting or touching the eyelids, measurement repetitions, and alteration of the tear film. ${ }^{1 \text { (p. 33),6(p. 33),22 }}$ 


\section{Conclusion}

The results of this study indicate that the NCT used was a valid alternative to the GAT, which is considered the gold standard, only in Group 1 (eyes with an IOP between 10 and $15 \mathrm{mmHg}$ ). In Groups 2 and 3 (eyes with an IOP equal to or greater than $16 \mathrm{mmHg}$ ), as well as in Groups 4 (patients aged 40 to 59 years) and 5 (patients aged 60 years or older), the NCT overestimated the IOP.

The non-contact tonometer overestimates the measurement at higher pressures, does not replace the Goldmann tonometer, but may be a good screening tool that helps the measurement of IOP, especially in eyes with less than $15 \mathrm{mmhg}$, due to its ease of use. The results of the NCT depend on the brand, unit, and model used, and most NCT devices are more reliable for measuring lower eye pressures as observed in the present study, emphasizing the need to develop devices with greater accuracy at higher pressures to increase the level of reliability.

The limitation of the study was the performance of NCT with only one device brand, and a strength of the study was the stratification of participants by pressure range. Future studies comparing different non-contact devices (brand and model) with participants stratified by eye pressure range will be necessary to better understand their performance compared to the Goldmann tonometer in the measurement of intraocular pressure.

\section{Abbreviations}

IOP, intraocular pressure; GAT, Goldmann applanation tonometer; NCT, Non-contact air-puff tonometer.

\section{Ethics Approval}

Ethics approval was obtained from the research ethics committee of the Universidade do Oeste de Santa Catarina by number $3,412,730$.

\section{Author Contributions}

All authors made a significant contribution to the work reported, whether that is in the conception, study design, execution, acquisition of data, analysis and interpretation, or in all these areas; took part in drafting, revising or critically reviewing the article; gave final approval of the version to be published; have agreed on the journal to which the article has been submitted; and agree to be accountable for all aspects of the work.

\section{Funding}

No funding was received.

\section{Disclosure}

The authors declare no conflicts of interest for this work.

\section{References}

1. European Glaucoma Society. Terminology and guidelines for glaucoma. 4th ed; 2017. Available from: https://bjo.bmj.com/con tent/bjophthalmol/101/4/1.full.pdf. Accessed May 5, 2020.

2. Burr JM, Mowatt G, Hernández R, et al. The clinical effectiveness and cost-effectiveness of screening for open angle glaucoma: a systematic review and economic evaluation. Health Technol Assess. 2007;11(41):iii-iv, ix-x, 1-190. doi:10.3310/hta11410

3. American Academy of Ophthalmology. Preferred practice pattern guidelines. primary open-angle glaucoma. San Francisco; 2015. Available from: https://www.aaojournal.org/action/ showPdf?pii=S0161-6420\%2815\%2901278-6. Accessed April 10, 2020.

4. Brazilian Glaucoma Society. $3^{\circ}$ consenso brasileiro de glaucoma de ângulo aberto. São Paulo; 2009. Available from: https://www.sbglau coma.org.br/wp-content/uploads/2020/06/consenso03-v2.pdf. Accessed April 10, 2020.

5. Kass MA, Heuer DK, Higginbotham EJ, et al. The ocular hypertension treatment study: a randomized trial determines that topical ocular hypotensive medication delays or prevents the onset of primary open-angle glaucoma. Arch Ophthalmol. 2002;120(6):701-713. doi:10.1001/archopht.120.6.701

6. McCafferty SJ, Levine J, Schwiegerling J, Enikov ET. Goldmann applanation tonometry error relative to true intracameral intraocular pressure in vitro and in vivo. BMC Ophthalmol. 2017;17:2015. doi:10.1186/s12886-017-0608-y

7. Salim S, Linn DJ, Echols JR, Netland PA. Comparison of intraocular pressure measurements with the portable PT100 noncontact tonometer and Goldmann applanation tonometry. Clin Ophthalmol. 2009;3:341-344. doi:10.2147/opth.s5537

8. Yilmaz I, Altan C, Aygit ED, et al. Comparison of three methods of tonometry in normal subjects: goldmann applanation tonometer, non-contact air puff tonometer, and Tono-Pen XL. Clin Ophthalmol. 2014;8:1069-1074. doi:10.2147/OPTH.S6391

9. Ogbuehi KC. Assessment of the accuracy and reliability of the Topcon CT80 non-contact tonometer. Clin Exp Optom. 2006;89 (5):310-314. doi:10.1111/j.1444-0938.2006.00068.x

10. Baqiatu NLS, Assfi R, Tham C, Azeera NAM. Performance of Huvitz HNT7000 non- contact tonometer in measuring intraocular pressure. IJMTFM. 2018;21(3and 4):154. doi:10.5958/09744614.2018.00056.6

11. Ahmad J, Khan MR, Naeem M, Arain ATM, Qazi ZDA. Accuracy of IOP measured by non-contact (air-puff) tonometer compared with goldmann applanation. GJMS. 2018;30(1):20-23.

12. Bukhari AS, Mirani AH, Shar MA, Shah SJSLA. Comparison of measurement of intraocular pressure between goldmann applanation tonometer and non-contact air puff tonometer. PJO. 2018;34 (1):63-66. doi:10.36351/pjo.v34i1.18

13. Ko Y-C, Liu CJ-I, Hsu W-M. Varying effects of corneal thickness on intraocular pressure measurements with different tonometers. Eye. 2005;19:327-332. doi:10.1038/sj.eye.6701458

14. Das S, Kiran Kumar L. Comparative study of intraocular pressure measured by non-contact, rebound and Goldmann applanation tonometer and their correlation with corneal thickness and true IOP in a general population. Indian J Clin Exp Ophthalmol. 2020;6 (1):41-49. doi:10.18231/j.ijceo.2020.010 
15. Tolomei LA, Hashimoto M, Mazeto CFS, et al. Uso da tonometria de ar em pesquisas populacionais - comparação com o tonômetro de Goldmann em indivíduos com suspeita de hipertensão ocular. Rev Bras Oftalmol. 2016;75(3):209-213. doi:10.5935/00347280.20160043

16. Farhood QK. Comparative evaluation of intraocular pressure with an air-puff tonometer versus a Goldmann applanation tonometer. Clin Ophthalmol. 2013;7:23-27. doi:10.2147/OPTH.S38418

17. Jacob CES, Selvim SST, Kuriakose T. Usefulness of the non-contact tonometry in out-patient screening. Asian J Ophthalmol. 2016;15 (2):111-118.

18. Nakao Y, Kiuchi Y, Okimoto SA. Comparison of the corrected intraocular pressure obtained by the corvis ST and reichert 7CR tonometers in glaucoma patients. PLoS One. 2017;12(1):e0170206. doi:10.1371/journal.pone.0173306

19. Trakanwitthayarak S. Comparison of intraocular pressure measurement between non-contact and goldmann applanation tonometry among glaucoma patients in ratchaburi hospital. J Med Assoc Thai. 2020;103:819-823. doi:10.35755/jmedassocthai.2020.08.10279
20. Luebke J, Bryniok L, Neuburger M, et al. Intraocular pressure measurement with Corvis ST in comparison with applanation tonometry and Tomey non-contact tonometry. Int Ophthalmol. 2019;39:2517-2521. doi:10.1007/s10792-019-01098-5

21. Mahsud H, Saleem MW, Muhammad R, Saleem M, Ayaz M. Comparison of intraocular pressure measured with goldmann applanation tonometer and non-contact air-puff tonometer. Gomal J Med Sci. 2016;14(2):467-472.

22. McCafferty SJ, Enikov ET, Schwiegerling J, Ashley SM. Goldmann tonometry tear film error and partial correction with a shaped applanation surface. Clin Ophthalmol. 2018;12:71-78. doi:10.2147/OPTH. S152492
Clinical Ophthalmology

\section{Publish your work in this journal}

Clinical Ophthalmology is an international, peer-reviewed journal covering all subspecialties within ophthalmology. Key topics include: Optometry; Visual science; Pharmacology and drug therapy in eye diseases; Basic Sciences; Primary and Secondary eye care; Patient Safety and Quality of Care Improvements. This journal is indexed on PubMed

Submit your manuscript here: https://www.dovepress.com/clinical-ophthalmology-journal
Dovepress

Central and CAS, and is the official journal of The Society of Clinical Ophthalmology (SCO). The manuscript management system is completely online and includes a very quick and fair peer-review system, which is all easy to use. Visit http://www.dovepress.com/ testimonials.php to read real quotes from published authors. 